\title{
14
}

\section{Information technology curriculum for engineering management qualification}

\author{
Fumihiko Kamijo \\ Tokai University and IT Engineers Examination Committee \\ 1117 Kitakaname, Hiratsuka, Kanagawa, Japan \\ +81-463-58-1211,e-mail:fktokai@cc.u-tokai.ac.jp
}

\begin{abstract}
The Information Technology Engineers Examination (ITEE) introduced a set of new exam curricula, with a major modernisation of exam system. New ITEE system enforced the EDPmanagement parts. The following discussion is an analysis of System Analyst (AN) curriculum for Type AN exam, which is a typical example of a management level examination. It assumes a Corporate Information Officer as a candidate.

A good balance of IT knowledge and management skills in the curriculum is a problem. AN- curriculum has a separate IT-curriculum named CLASS I. CLASS I is developed as the common part of ITEE technical curricula. It is an IT-based, professional, detailed program. Consequently, it puts a heavy burden to manager type candidates.

A discussion on the appropriateness of AN-curriculum with CLASS I and the effects of its introduction to the ITEE system follow.
\end{abstract}

Keywords

Curriculum Development; Industry Education; Testing, Certification, and Licensing

\section{INTRODUCTION}

There are very few Japanese 'management' schools of graduate level. The numbers of MBA and DBA are almost negligible in our business community. Most schools of business administration major in accounting, manufacturing control, and occasionally business planing, all for daily practices. Japanese employers normally conduct management education and training equivalent to American or European business schools in their practical business environments.

Management of IT(Information Technology) is not an exception. Consequently, contents of IT training in Japan are different by organisation. We need a common measure for the nonstandard training results. ITEE (Information Technology Engineers Examination) is a governmental exam to meet to the requirement.

The recently modernised ITEE increased exam classifications for EDP (Electronic Data Processing) managers from one exam type to three. Each exam type has a corresponding curriculum for training. It is open to public. This paper is to show changes of ITEE for IT managers and to evaluate the effects of modernisation by an analysis of a typical EDP management curriculum, i.e., AN-curriculum. 


\section{ITEE}

ITEE is designed for the people who want the official achievement certificates of their professional experience and technical knowledge. They normally get the training using OJT (on-the-job training) systems provided by employers.

\begin{tabular}{ll} 
Table 1 ITEE (old) Exam types & \\
\hline System Auditor Exam (SA) & for auditor level (management level) \\
System Engineer Exam (SE) & for system analyst and designer level \\
Online System Engineer Exam & for system analyst and design \\
Type I Exam & for senior programmer \\
Type II Exam & for junior programmer \\
\hline
\end{tabular}

Originally ITEE had five types of examinations as shown in Table 1. Recent drastic advancements of computer technology and application engineering made old ITEE almost obsolete. JITEC (Japan Information Technology Engineer's Examination Center) and ITEE Exam Committee designed a new exam system that consisted of twelve exam-types. The new scheme has the exam types for managers (three types), for technical managements (two types), for specialists (four types), for engineers (two types) and for end-users (one type). Table 2 is a list of the new exam types. An increase of managerial level exam types is the most significant change (MITI,1995).

AN-curriculum for system analysts is chosen for the analysis, because it is one of the three exam types of managerial level. The characteristics of the three exam types are almost selfexplanatory. A Systems Analyst (Type AN) is responsible for planing a CIS (corporate information system) at a level of CIO (Chief Information Officer). A Project Manager (Type $\mathrm{PM}$ ) is responsible for its realisation with the development team management. Finally a Systems Auditor (Type AU) has a task to review the appropriateness of planning, developing and operating processes.

Table 2 ITEE (new) Exam types

\section{Exam type}

Systems Analyst (AN)

Systems Auditor (AU)

Project Manager (PM)

Application Systems Design

Engineer (AE)

Systems Operation Management

Engineer (SM)

Software Design and Production

Engineer (PE)

Network Specialist (NW)

Database Specialist (DB)

Microsystems Specialist(ME)

ClassI

ClassII

System Administrator (AD)

\begin{tabular}{|c|c|c|}
\hline min. & $\begin{array}{l}\text { experience } \\
\text { (years) }\end{array}$ & level \\
\hline 27 & 6 & management \\
\hline 27 & 6 & management \\
\hline 27 & 6 & $\begin{array}{l}\text { management } \\
\text { technical }\end{array}$ \\
\hline 25 & 6 & $\begin{array}{l}\text { management } \\
\text { technical }\end{array}$ \\
\hline 25 & 6 & management \\
\hline - & 6 & specialist \\
\hline - & 6 & specialist \\
\hline - & 6 & specialist \\
\hline - & 6 & specialist \\
\hline - & $3-5$ & senior engineer \\
\hline - & $1-3$ & junior engineer \\
\hline - & - & end user \\
\hline
\end{tabular}




\section{MANAGEMENT EDUCATION AND THE NEW EXAM SYSTEM}

Japanese corporations hire new college graduates as junior operational staffs or junior specialists. They train newly-hired people by OJT. This freshman training process resembles the business school education, although there is no schooling system. The ITEE system measures the achievements and the experience levels gained by OJT in the area of EDP.

\subsection{Curriculum for System Analyst}

Unlike a specialist type naming of "System Analyst," Type AN exam has an objective to set a target level of managerial training in an EDP environment. It requires that a successful candidate be more than 27 years old and can play the role of CIO.

The major task of AN-curriculum is to give a good reference of managerial and technical achievement levels for the people in the business world. We assume a System Analyst candidate has worked out OJT in their business organisations for more than six years. Therefore, he has full managing skill and sufficient experience in IT as well.

A Systems Analyst can carry out the following tasks in real business environments.

Full understanding of the corporate business strategies,

Planning a corporate information strategy,

Create a business-practice improvement plan,

Design a CIS,

Establish a system development plan, and

Evaluate the existing CIS.

Table 3 Curriculum of system analyst

\begin{tabular}{lrrrc}
\hline TOPICS & LEC & PRA & TOT & M \\
1. Introduction to Management & & & & \\
1.1 Management in General & 6.0 & & 6.0 & $\mathrm{M}$ \\
1.2 Management Information System & 9.0 & & 9.0 & $\mathrm{M}$ \\
1.3 System Evaluation and Auditing & 8.0 & & 8.0 & $\mathrm{M}$ \\
1.4 Risk Analysis and Security & 9.0 & & 9.0 & $\mathrm{M}$ \\
2. Corporate Information Strategies & & & & \\
2.1 Business Environments & 10.5 & 7.0 & 17.5 & $\mathrm{M}$ \\
2.2 Information Strategy & 11.5 & 9.0 & 20.5 & $\mathrm{M}$ \\
3. Corporate Information Plan & & & & \\
3.1 Master Plan & 2.5 & & 2.5 & $\mathrm{M}$ \\
3.2 Planning Methods & 2.0 & 1.5 & 3.5 & $\mathrm{M}$ \\
3.3 Process Modeling & 3.5 & 8.0 & 11.5 & $\mathrm{M}$ \\
3.4 Information System Modeling & 5.0 & 8.0 & 13.0 & $\mathrm{M}$ \\
3.5 Problem Identification and Analysis & 3.5 & 3.0 & 6.5 & $\mathrm{M}$ \\
3.6 Long Term Plan of CIS & 9.0 & 11.5 & 20.5 & $\mathrm{M}$ \\
3.7 Evaluation and Accreditation & 3.0 & 1.0 & 4.0 & $\mathrm{M}$ \\
4. Development Plan & & & & \\
4.1 Development Planning & 8.5 & 6.5 & 15.0 & $\mathrm{M}$ \\
4.2 Objective Definition & 5.0 & 10.5 & 15.5 & $\mathrm{M}$ \\
4.3 System Definition & 7.0 & 6.0 & 13.0 & $\mathrm{M}$ \\
4.4 Preparation of Development Plan & 8.5 & 10.5 & 19.0 & $\mathrm{M}$ \\
4.5 Evaluation and Accreditation & 2.0 & 2.5 & 4.5 & $\mathrm{M}$ \\
\hline
\end{tabular}

M: Required Topic

LEC: Lecture

PRA: Practice

TOT: Total (hours) 
The most important topic of AN-curriculum is how to plan a CIS. One must know management practices well to understand a CIS. Therefore, the curriculum allocates 32 hours to general management practices, and additional 38 hours to the corporate information strategies (including laboratory work).

The main body of AN-curriculum consists of the topics related to planning methodologies and practices (61.5 hours). The topic of plan development has 60 hours of time allocation. A quick browsing of the curriculum follows: (see Table 3)

1) Introduction to Management (lecture: 32 hours)

- What is a CIS? How to build the system? How to evaluate a completed system?

- Most of the topics are review subjects for exam candidates. A candidate who trained by OJT often has biased knowledge by his own company's business practices. This part of the curriculum is to give him the knowledge of a generalised CIS.

- The risk management is a subject that becomes very important recently. The weight placed on this topic is only $4.5 \%$ of the total time. It is necessary to increase the weight or it is better to add an additional chapter dedicated to security.

2) Corporate Information Strategies (lecture: 22 hours, practice: 16 hours)

- A relationship between business environments and information strategies is a major topic. Its practice portion is easily replaceable by daily activities. Apparently there are differences of strategies by organisation. There is no 'standard version' in this area. The curriculum shows only a common model.

3) Corporate Information Plan (lecture: 28.5 hours, practice: 33 hours)

- This subject consists of lectures on various planning methods, on the processes of planning (from a master plan to details), and on additional topics as a long term planning.

- Practice subjects include system modeling and long term plan making. There are not many chances to build system models using the standard methodologies. It may be a necessary area for the candidates to enforce their experience and review their local procedures by the light of theoretical processes.

4) Development Plan (lecture: 31 hours, practice: 36 hours)

- The system development plan consists of objective definitions, system definitions, a development plan, a management plan for a development process and a system evaluation plan. Among those, the management topics of development process are reserved for a Project Manager.

- The big AN-curriculum asks a candidate to study EDP management for about 200 hours. The practice based assignments occupies about $2 / 3$ of the total hours, with considerations to the busy daily life of a business person in EDP field.

- AN-curriculum has no IT topics, although the exam covers IT based on CLASS I (Senior Programmer) curriculum. The weight for the IT topic is roughly one third, i.e., 150min out of total exam time of $360 \mathrm{~min}$.

\section{PROBLEMS AND POSSIBLE SOLUTIONS}

1) Relationship between ITEE Curricula and Japanese Official Education ITEE and its curricula are independent from Japanese standard school system(IPSJ,1992- 
3)(Kamijo,1990). They are independent, because the contents of IT education in Japanese schools is significantly different from the real world data processing environments by several reasons(Kamijo, 1992).

First, the school system considers the IT topics as a part of professional training subjects. Commercial high schools and engineering high schools introduced educational computers many years ago, but professional high schools were relatively small part of our high school system. General high schools did not take part in the IT education at all, because, the university admission test system did not introduce IT subjects until very recent reorganisation. It is not effective yet.

Secondly, the IT subjects occupy a small part of the selective subjects in the admission tests even after the reorganisation. Very few high school graduates have experienced any basic computer science. They sometimes learn BASIC as the educational programming language that ITEE does not accept any more.

The business sector has to conduct almost all of practical IT training using OJT as major means. It is one of the reasons why we have non-computer major graduates as a majority of IT engineers.

2) Too much Requirements to ITEE by the Business Sector

The ITEE curricula consist of many independent subjects that cover extremely wide range of IT applications. It is very difficult for teaching and training system to cover all of them in a limited time. Year-long training period of OJT or two to three years of full time professional school education is only measure to meet to the business sector requirements.

Is this new ITEE curriculum system a good solution to high level, wide scope business sector requirements? I believe the answer to the question is 'no'.

ITEE Curriculum Committee asked to the business community for its requirements. It was the first attempt to ask employers on the quality of engineers. A list of job definitions and IT profession classifications were two outcomes(MITI,1995). The committee developed a role map of IT professionals, first. A new exam-type classification shown in Table 2 was a natural extension of the roll classification. They developed the ITEE curricula in parallel to the exam types.

Whole process itself was ideal, except that it did not take the characteristic of respondents to the call for requirements, in account. They were high-level management people, neither trainers nor educators. This was the reason they got a widespread requirement response. The problem caused by application of CLASS I to the managerial exam types clearly revealed a discrepancy between the idea and the reality. CLASS I curriculum contains knowledge topics related to Computer Science, Hardware Architecture, Operating Systems, Database Systems, Software Engineering, Human Interface, System Security, Communication System, Problem Solving and Group Communication as mandatory subjects. It is good for engineering specialists, but not for EDP managers.

\section{3) Classification of Subjects}

Due to the governmental nature of ITEE, JIPDEC (Japan Information Processing Development Center) developed all of the ITEE curricula using a large committee system. The committee system is one of the reasons why the curricula became so large.

There was a curriculum development committee for each type of exam. Besides the development committee, it was necessary to set up a design committee to make a uniform basic design of the curriculum system. This mechanism was very efficient to complete the complex job in relatively short time, but it was only possible without interfacing to the established and subject-based curricula(Couger,1972)(Nunamaker,1981)(Tucker,1991). 
Consequently, ITEE curricula consist of different subject classification from conventional university subjects. It is the reason the formal educational organisations cannot easily subscribe ITEE curricula(Kamijo, 1992).

\section{4) Lack of Teachers and Training Environments}

The scarcity of teachers and trainers in IT organisations is a never solved problem. It is a basic shortcoming of OJT scheme. OJT without a good trainer tends to bring up a helper-type engineer, not a manager.

There are very few educational organisations for IT teaching staff in Japan. IT organisations have to prepare own schemes without any standard. ITEE curricula may help the organisations by a supply of textbooks and teaching materials, but it has no mechanism to train any teaching staff.

\section{5) Is the IT Experience Measurable?}

This is the very basic question posed on the principle of ITEE. It is understandable that in an environment of data processing, an experienced person is more capable of solving daily tasks. The class room education cannot fill the experience part of requirements of business sector, instead, it can develop the basic ability to continue a self-study to get the experience. The environment of data processing changes very quickly. Anybody who had picked up IT skills by daily EDP operations would become obsolete when the EDP environment had evolved significantly. It happens very often in our business life.

Measuring such experience is another matter. It is easy to reach a certain level of EDP experience through daily operations. Any paper test like ITEE has limitations when they try to assess the experience by knowledge based questionnaires(Kamijo, July 1992).

ITEE has a three-part questionnaire. Part I gives a series of assessment on IT knowledge and is given in a format of multiple choice questions. Part II consists of case-based questions to measure problem-solving ability. Part III asks to a candidate to write a short essay on the given topic based on his experience. A topic could be something like; "How to solve such a problem under given circumstances if your management insists you to change a company's order entry system to more efficient style to enhance a particular section's profits?".

We know that the experience-measuring ability of ITEE is not particularly powerful. But, in the long history of ITEE, we believe this mechanism have worked well(Kamijo,1993).

\section{CONCLUSION}

First major attempt to modernise the ITEE system has completed its first cycle. It seems a success as far as we could see from several indices like the annual number of candidates, the business community's acceptance, the reputation to questionnaires collected from many ITEE watchers like journalists. It is the first attempt for the ITEE system to prepare and reveal its curricula. Their volumes are too large for the candidates, the educators or the OJT trainers for a class room usage, though.

In this paper, AN-curriculum is a target of analysis. It contains managerial topics only. Type AN exam borrows most of IT related topics from CLASS I curriculum, although about $1 / 3$ of Type AN exam hours is allocated to IT.

AN curriculum puts a large weight to planning processes. But there is a difficulty to introduce it to the official education system due to the difference of educational principles. The business sector requirements, the measurement of levels of IT experiences, in particular, caused the discrepancy. It may be better to reshuffle the requirements and skim the curriculum. 
CLASS I curriculum did not apply a conventional subject configuration of computer science. The nonstandard classification of the subjects increased difficulty to use it in the formal classes that meet Japanese university-education requirements. It is one of the causes of the scarcity of teachers or trainers in IT organisations.

There is a question of measuring IT experiences by written questionnaires. It is the problem of the ITEE system policy and has to be solved in the future.

\section{REFERENCES}

MITI(1995). New Information-Technology Engineers Examination System. Ministry of International Trade and Industry, Japan Information-Technology Engineers Examination Center and Japan Information Processing Development Center (Tokyo, Japan).

Couger,J.D.(Ed.)(1972). Curriculum Recommendations for Undergraduate Programs in Information Systems. CACM 15,5(May 1972).

Nunamaker,Jr.,J.F.(1981) et al(Eds). Information Systems Curriculum Recommendations for the 80s: Undergraduate and graduate Programs, ACM(New York).

Tucker, A. B.(1991), et al. Computing Curricula 1991 - Report on the ACM/IEEE-CS Joint Curriculum Task Force. ACM Press, New York.

Kamijo, F. and Nakayashiki, M.(1990). IT Engineers Examination and CAROL Courseware. Proc. IFIP TC3 Fifth World Conference on Computers in Education, Sydney, 541- 548.

Information Processing Society of Japan(IPSJ)(1992-3). A Research Report on Computer Science Curriculum in Japanese Universities and Colleges (both in Japanese language, Titles translated only for reference purposes).

Kamijo,F. and Nakayashiki, M.(1992). Difficulties in Integrating the IT Qualification Test and Training Curriculum. J. Systems Integration, 2(1992)291-312.

Kamijo, F. and Nakayashiki, M(1992). Evaluation of the ITEE Exam Questions. Proc. IFIP WG3.4 Working Conference on Professional Development of Information Technology Professionals, Singapore (July 1992)179-186.

Kamijo, F., Yuchao, Z. and Aoki, T.(1993). Statistical Analysis of ITEE Exam Questions. Proc. IFIP WG3.4/SRIG-ET(SEARCC) International Working Conference '93 on Software Engineering Education, Hong Kong (Sept. 1993).

\section{BIOGRAPHY}

Fumihiko Kamijo is Professor of the Information Science Laboratory, Tokai University (1990-); Chair of ITEE Exam Committee, JPPEC (1984 - ); Trustee of Japan Society for Security Management(1987 - ); Members of Assoc. for Computing Machinery, IEEE/Computer Society, Information Processing Society of Japan. He also chairs and is a member of various government technical committees. Previous activities include: Managing Director, Information-technology Promotion Agency (1985 - 1991); Member, Advisory Committee of Japan Society for Software Science and Technology (1983 - 85); Member, Advisory Committee of Japan Society for Artificial Intelligence (1985 - 87); BSEE, Tokyo University(1957), SM(Management), MIT(1967). Certified Technical Consultant (Science and Technology Agency, Japan). 